\title{
Selective decrease in the DNA base excision repair pathway in squamous cell cancer of the esophagus
}

Pramod Bonde, MD, MS, FRCS, ${ }^{a}, *$ Daqing Gao, PhD, ${ }^{a}, *$ Lei Chen, PhD, ${ }^{a}$ Mark Duncan, MD, ${ }^{b}$ Tomoharu Miyashita, $\mathrm{MD}^{\mathrm{c}}$ Elizabeth Montgomery, MD, ${ }^{c}$ John W. Harmon, MD, FACS, ${ }^{b}$ and Chiming Wei, MD, PhD, FACC, FAHA ${ }^{a}$

Supplemental material is available online.
From the Cardiothoracic-Renal Research Program, ${ }^{\mathrm{a}}$ the Department of Surgery, ${ }^{\mathrm{b}}$ and the Department of Pathology, ${ }^{\mathrm{c}}$ Johns Hopkins University School of Medicine, Baltimore, Md

Read at the Eighty-sixth Annual Meeting of The American Association for Thoracic Surgery, Philadelphia, Pa, April 29-May 3, 2006.

Pramod Bonde is supported by the RVH fellowship, RRG funding from Queens University, Dowager Countess Eleanor Peel Foundation, and St Jude Scholarship of Society of Cardiothoracic Surgeons of Great Britain and Ireland.

Received for publication April 10, 2005; revisions received May 22, 2006; accepted for publication June 7, 2006.

Address for reprints: Chiming Wei, MD, PhD, FACC, FAHA, $600 \mathrm{~N}$ Wolfe St/ Blalock 1206, Johns Hopkins University School of Medicine, Baltimore, MD 21205 (E-mail: cmwei@jhmi.edu).

*Drs Bonde and Gao contributed equally to this work.

J Thorac Cardiovasc Surg 2007;133:74-81

$0022-5223 / \$ 32.00$

Copyright $\odot 2007$ by The American Association for Thoracic Surgery

doi:10.1016/j.jtcvs.2006.06.050
Objectives: Oxidative damage can lead to a highly mutagenic 8-oxoguanine lesion, which mispairs with adenosine residues, leading to $\mathrm{G}: \mathrm{C} \rightarrow \mathrm{T}: \mathrm{A}$ transversions. In mammalian cells 8-oxoguanine glycosylase initiates the DNA base excision repair pathway to repair the 8-oxoguanine lesion. To date, there is no information regarding oxidative DNA damage and repair pathways in esophageal cancer. Therefore we designed the current study to demonstrate the DNA damage and repair pathways in esophageal cancer by expression of 8-oxoguanine glycosylase in reflux-induced and mutagen (methyl-n-amyl nitrosamine)-induced DNA damage and apoptosis in esophageal tumors.

Methods: Gastroduodenal reflux was surgically created in male Sprague Dawley rats $(\mathrm{n}=120)$. Half of the animals received methyl-n-amyl nitrosamine. Animals not undergoing operations served as control animals $(n=10)$. The experiment concluded 30 weeks postoperatively. Immunohistochemistry for 8-oxoguanine and 8-oxoguanine glycosylase was assessed by 2 independent observers. Protein expression was assessed by using the Western blot method.

Results: There was significantly more DNA damage in both adenocarcinoma ( $\mathrm{n}=$ $15)$ and squamous cell carcinoma $(\mathrm{n}=19)$, as exemplified by positive 8 -oxoguanine expression compared with that seen in control animals $(P<.05)$. 8-Oxoguanine glycosylase was several folds upregulated in adenocarcinoma $(P<.05)$, but there was significantly decreased expression in squamous cell carcinoma $(P<.01)$. The apoptosis was assessed as caspase-dependent and caspase-independent pathways, and both were active and correlated well with 8-oxoguanine expression.

Conclusion: These results demonstrate the selective decrease in the DNA base excision repair pathway in combined reflux and methyl-n-amyl nitrosamine-induced squamous cell cancer of the esophagus.

$\mathrm{P}$ opulation-based studies in the Western Hemisphere have shown a steady and rapid increase in the incidence of esophageal adenocarcinoma. ${ }^{1,2}$ At the same time, the incidence of esophageal squamous cell cancer has remained unchanged. The cause for this epidemic is still not clear, although some of the studies have suggested that the increase in esophageal adenocarcinoma might be related to a similar increase in the incidence of symptomatic gastroesophageal reflux disease (GERD) witnessed in the last few decades..${ }^{3,4}$ Population studies have demonstrated a strong and causal relation between GERD and the risk of development of esophageal cancer. ${ }^{3}$ GERD is known to lead to repeated inflammation of the esophageal mucosa. Continuing reflux injury to the esophageal mucosa can lead to the development of metaplastic columnar epithelium. If the underlying reflux continues unabated, the metaplastic Barrett's epithelium is at risk of dysplasia and eventually malignant transformation. Several animal studies suggest that the gastroduodenal contents are 


\author{
Abbreviations and Acronyms \\ AIF $=$ apoptosis inducible factor \\ BER = base excision repair \\ $\mathrm{DAB}=$ diaminobenzamide tetrahydrochloride \\ GERD = gastroesophageal reflux disease \\ MNAN = methyl-n-amyl nitrosamine \\ OGG1 $=8$-oxoguanine DNA glycosylase \\ 8-oxoG $=8$-oxo-7,8-dihydro-2' deoxyguanosine \\ PARP $=$ poly (adenosine diphosphate-ribose) \\ polymerases \\ PBS = phosphate-buffered saline \\ ROS $=$ reactive oxygen species \\ TUNEL $=$ terminal deoxynucleotidyl \\ transferase-mediated dUTP nick end \\ labeling
}

injurious to the esophageal mucosa and can lead to Barrett's metaplasia and progress to cancer. ${ }^{5-7}$

Chronic production of reactive oxygen species (ROS) might play an important role in the modulation of GERDassociated esophageal mucosal injury. ${ }^{8,9}$ ROS, including superoxide radical, hydrogen peroxide, hydroxyl radical, and the peroxynitrite radical, play a critical role in the pathogenesis of GERD-mediated esophageal mucosal damage and can be mutagenic to esophageal mucosa., ${ }^{9,10}$

One of the most stable and deleterious products of oxidative DNA damage is 8-oxo-7, 8-dihydro-2' deoxyguanosine (8-oxoG). ${ }^{11}$ Unrepaired 8-oxoG lesions in DNA can lead to A/8-oxoG mismatches during DNA replication and result in $\mathrm{G}: \mathrm{C} \rightarrow \mathrm{T}$ :A mutations. ${ }^{12,13}$ 8-Oxoguanine DNA glycosylase $(O G G 1)$ catalyses the removal of 8-oxoG through the base excision repair (BER) pathway. ${ }^{14}$ Increased concentration of $O G G l$ is shown in various organs and tissues. ${ }^{14}$ There is some evidence that polymorphism in this gene might increase the risk of esophageal cancer. ${ }^{15}$

The role of DNA damage and the BER pathway has not been investigated directly in a progressive model of esophageal squamous carcinoma and adenocarcinoma. However, DNA repair is an important way of developing therapeutic resistance in cancer cells. Several of these proteins are emerging as therapeutic targets in chemoprevention. ${ }^{16,17}$ We report our results on BER pathway activity in an animal model of GERD, which can lead to esophageal cancer. We hypothesize that the malignant transformation in the esophageal mucosa is a result of chronic disparity between DNA injury and repair induced because of GERD.

\section{Materials and Methods}

Animals received humane care in compliance with the "Guide for Care and use of Laboratory Animals" published by the National Research Council (National Academy Press, 1996). The Institutional Animal Care and Use Committee approved all the proce- dures in this study. All procedures were performed under aseptic conditions, and anesthesia was achieved with a combination of ketamine and acepromazine. Mixed gastroduodenal reflux ( $\mathrm{n}=$ 120) was induced in 10-week-old, male Sprague Dawley rats, (200-250 g; Harlan, Indianapolis, Ind). The animals were allowed 2 weeks to acclimatize before the operation and were housed at a temperature of $20^{\circ} \mathrm{C}$ to $22^{\circ} \mathrm{C}$, a humidity of $70 \%$, and a 12-hour alternating light-dark cycle. The rats were fasted overnight but allowed water ad libitum until the day of the operation. Briefly, the esophagus was mobilized, preserving the vagus nerves, and anastomosed side to side to the first part of the duodenum immediately distal to the pyloric sphincter. The anastomotic sutures were carefully placed a millimeter from the edge of the pyloric sphincter so as to achieve duodenal, as well as gastric, reflux simultaneously in the lower esophagus before neutralization of the gastric contents can take place in the duodenum. Care was taken to preserve the pyloric sphincter and cardiac sphincter to maintain the integrity of the stomach. Once the animals awoke, they were allowed water ad libitum. Feeding recommenced the following day. Animals received appropriate analgesia during the perioperative and postoperative periods. Another group undergoing operations $(n=60)$ received methyl-n-amyl nitrosamine (MNAN) injected intraperitoneally, $25 \mathrm{mg} / \mathrm{kg}$ body weight (lethal dose, $50 \%$ or median lethal dose), for 4 doses administered each week for 4 weeks beginning 2 weeks after recovery from surgical intervention. Ten animals served as control animals that had undergone no operation or MNAN administration. The experiment concluded 30 weeks postoperatively.

\section{Harvesting of the Tumors}

Animals were anesthetized as described before. Abdominal and thoracic viscera were exposed through a midline incision, and the tumor was assessed for size and extent. The esophagus was mobilized from the neck down to the anastomosis. The tumors were identified and carefully dissected away from the liver and adjoining structures. The esophagus was opened longitudinally to expose the lumen, and half of the esophagus was preserved in $10 \%$ formalin for histologic examination and another half in liquid nitrogen for immunoblot examination.

Histologic gradations were defined as follows.

Hyperproliferative esophagitis. A specimen was defined as having squamous hyperplasia when there was papillary elongation or basal cell hyperplasia (normal, $\leq 3$ cell layers in thickness; mild, 4-8 cell layers; moderate, 9-12 cell layers; severe, $>12$ cell layers).

Papillomatosis. Papillomatosis was the term chosen to describe a common finding of basal cell hyperplasia, papillary elongation, and hyperkeratosis. A squamous papilloma was diagnosed when there was a localized papillary proliferation of benign squamous epithelium.

Columnar metaplasia (Barrett's esophagus). Columnar metaplasia was defined as the presence of unequivocal columnar epithelium (intestinal-type goblet cells) above the anastomosis (confirmed by means of periodic acid-Schiff and Alcian Blue staining).

Dysplasia and malignant transformation. Diagnosis of dysplasia was based on the abnormal cell polarity, maturation, nuclear atypia, and mitotic figures. Tumors were defined on the basis of malignant cells infiltrating the mucosa or basement membrane of the esophageal wall. Malignant transformation was graded as 
carcinoma in situ and squamous cell carcinoma in tumors with a pure squamous morphology; tumors with definite adenocarcinomatous elements were classified as adenocarcinomas. Mucin secretion was confirmed on mucicarmine staining. A mixed element of squamous and adenomatous features was classified as adenosquamous carcinoma.

\section{Determination of DNA Damage}

Formalin-fixed and paraffin-embedded sections were evaluated for 8-oxoG with anti-8-oxoG antibody (Trevigen, Gaithersburg, Md), as reported previously. ${ }^{18}$ Briefly, the slides were fixed and washed with phosphate-buffered saline (PBS), $\mathrm{pH} 7.4$, and incubated for 40 minutes at $37^{\circ} \mathrm{C}$. The DNA was denatured by soaking the slides in $4 \mathrm{~N} \mathrm{HCl}$ for 7 minutes. After incubation with $50 \mathrm{mmol} / \mathrm{L}$ Tris base for 5 minutes at room temperature and 2 washings with PBS, $10 \%$ fetal bovine serum was added for 1 hour at room temperature to block nonspecific staining sites. Next, slides were incubated with $3 \% \mathrm{H}_{2} \mathrm{O}_{2}$ for 30 minutes at room temperature to block endogenous peroxidase. Thereafter, slides were incubated with primary anti-8-oxoG monoclonal antibody (diluted 1:100 in 10 $\mathrm{mmol} / \mathrm{L}$ Tris- $\mathrm{HCl}, \mathrm{pH} 7.5,10 \%$ serum) overnight at $4^{\circ} \mathrm{C}$, rinsed twice with PBS, and incubated with secondary anti-mouse antibody (1:100) conjugated with $20 \mu \mathrm{g} / \mathrm{mL}$ streptavidin-horseradish peroxidase in $1 \times \mathrm{PBS}$ for 1 hour at room temperature. After staining with diaminobenzamide tetrahydrochloride (DAB; Dako Corp, Carpinteria, Calif) and counterstaining with methyl green, slides were examined under a light microscope. The percentage of cells staining positive for 8-oxoG was quantified as follows: No. of positive cells Total no. of cells $\times 100=\% 8-o x o G(+)$ cells.

\section{Immunohistochemical Staining}

Immunohistochemical staining was performed to determine the expression and localization of the DNA repair enzyme $O G G 1$ and apoptosis-related genes, such as apoptosis inducible factor (AIF), poly (adenosine diphosphate-ribose) polymerases (PARP), cytochrome $\mathrm{C}$, and caspase-3. Tissues were dehydrated and embedded in paraffin, and sections were cut to 5- $\mu$ m thickness. After samples were deparaffinized, blocked with $10 \%$ donor goat serum in PBS, and incubated with primary antibodies diluted in $10 \%$ donor goat serum and $0.3 \%$ Triton-X 100 for 20 hours at $4{ }^{\circ} \mathrm{C}$, the primary antibodies were used at a dilution of 1:100 against $O G G 1$, PARP, AIF, cytochrome $\mathrm{C}$, or caspase-3, respectively. After endogenous peroxidase activity was quenched by exposure of the slides to $0.5 \% \mathrm{H}_{2} \mathrm{O}_{2}$ in PBS for 15 minutes, the slides were washed in PBS and incubated with second antibody with horseradish peroxidaseconjugated anti-rabbit IgG (diluted 1:100; Santa Cruz Biotechnology, Inc, California, Calif). Finally, the sections were stained with DAB (DAKO Corp) and counterstained with hematoxylin, mounted, and reviewed. Two trained independent observers reviewed the sections without knowledge as to the respective groups from which the tissue was harvested, and at least 10 sections were reviewed per specimen. The specificity of positive staining was further confirmed by means of substitution of donor rabbit serum instead of primary antiserum. The positive staining was assessed by means of microscopic examination of the final slides and evaluated as to the quantification of the degree of staining as 0 (no staining), 1 (minimal intensity), 2 (mild intensity), 3 (moderate intensity), and 4 (maximal intensity), and the percentage of positive staining area in the entire section was examined ( $0 \%$ to $100 \%)$. The specificity of positive staining was further confirmed by means of substitution of normal rabbit serum instead of primary antiserum.

\section{Western Blot Analysis}

Tissue samples were homogenized in a lysis buffer $(0.1 \mathrm{~mol} / \mathrm{L}$ $\mathrm{NaCl}, 0.01 \mathrm{~mol} / \mathrm{L}$ Tris- $\mathrm{HCl}$ [pH 7.5], $1 \mathrm{mmol} / \mathrm{L}$ ethylenediamine tetraacetic acid, and $1 \mu \mathrm{g} / \mathrm{mL}$ aprotinin) and then centrifuged at $7000 \mathrm{~g}$ for 15 minutes at $4^{\circ} \mathrm{C}$. Supernatants were used as protein samples. Sodium dodecylsulfate-polyacrylamide gel electrophoresis was performed by using $10 \%$ polyacrylamide gel under nonreducing conditions. Thirty micrograms of protein was separated and transferred to nitrocellulose membrane by means of electroblotting. After transfer, the membrane was blocked for 1 hour in $10 \%$ nonfat dry milk (Bio-Rad, Hercules, Calif) and $0.1 \%$ Tween-20 in PBS to block nonspecific binding, and then the membranes were incubated with primary (1:500) and secondary (1:1000) antibodies. Detection was performed with the Enhanced Chemiluminescence kit (Amersham Pharmacia Biotech, Piscataway, NJ). Monoclonal antibodies against actin (Ab-6; Oncogene Research Products, Cambridge, Mass) were used as controls for equal protein loading. Another membrane was stained without the primary antibody to ascertain specific binding of the antibody for the protein.

\section{Terminal Deoxynucleotidyl Transferase-mediated dUTP Nick End Labeling Assay}

The terminal deoxynucleotidyl transferase-mediated dUTP nick end labeling (TUNEL) assay was performed in esophageal sections from each rat, according to our previously reported method, ${ }^{18}$ by using an ApopTag in situ apoptosis detection kit (Oncor, Gaithersburg, Md) to quantify the relative number of cells with DNA fragmentation. Briefly, after deparaffinizing the sections, tissue nuclei were stripped of proteins by means of incubation with $20 \mu \mathrm{g} / \mathrm{mL}$ proteinase $\mathrm{K}$ for 10 minutes. After treatment with $0.3 \%$ $\mathrm{H}_{2} \mathrm{O}_{2}$ in distilled water for 5 minutes, the sections were incubated with terminal deoxynucleotidyl transferase buffer (Boehringer Mannheim, Indianapolis, Ind), $30 \mathrm{mmol} / \mathrm{L}$ Tris (pH 7.2), 140 $\mathrm{mmol} / \mathrm{L}$ sodium cacodylate, and $1 \mathrm{mmol} / \mathrm{L}$ cobalt chloride containing terminal deoxynucleotidyl transferase buffer enzyme $(0.5$ $\mathrm{U} / \mathrm{mL}$, Boehringer Mannheim) and biotin-16-dUTP $(0.04 \mathrm{mmol} / \mathrm{L}$, Boehringer Mannheim) containing $30 \mathrm{mmol} / \mathrm{L}$ cobalt chloride in a humidified chamber at $37^{\circ} \mathrm{C}$ for 120 minutes. The reaction was terminated by incubating with $300 \mathrm{mmol} / \mathrm{L} \mathrm{NaCl}$ and $30 \mathrm{mmol} / \mathrm{L}$ sodium citrate for 15 minutes at $25^{\circ} \mathrm{C}$. After washing with 50 $\mathrm{mmol} / \mathrm{L}$ Tris- $\mathrm{HCl}$ ( $\mathrm{pH} 7.7$ ), sections were stained with $\mathrm{DAB} / \mathrm{H}_{2} \mathrm{O}_{2}$ solution and counterstained with hematoxylin. After 3 washes in Tris- $\mathrm{HCl}$ ( $\mathrm{pH}$ 7.7), sections were dehydrated in ascending ethanol series and immersed in xylene, and cover slips were mounted with Permount (Biomeda, Foster City, Calif). TUNEL- positive and TUNEL-negative cells were counted to determine the percentage of dead cells. Results are expressed as follows:

\section{No. of TUNEL ${ }^{+}$cells/Total no. of cells/Field $\times 100$.}

\section{Statistical Analysis}

Results of all quantitative studies are expressed as means \pm standard error. Statistical comparisons within each group were 


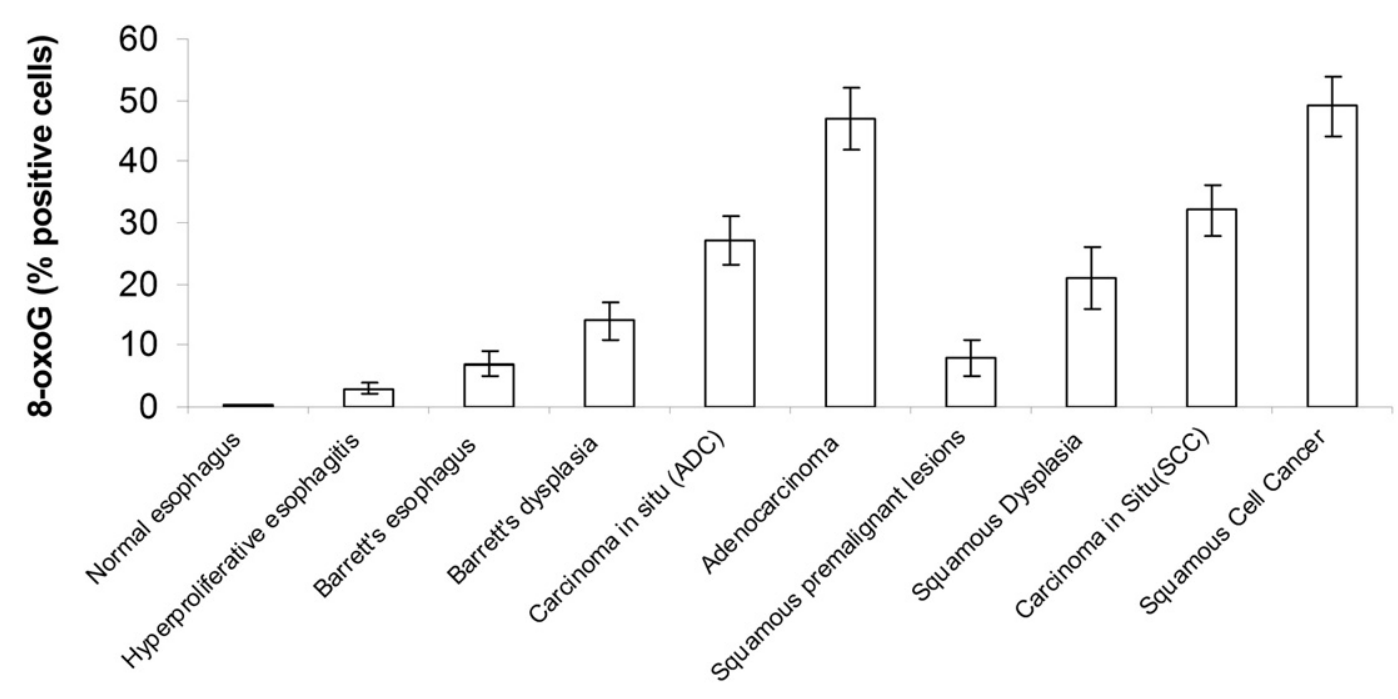

Figure 1. Staining score intensity for 8-0xo-7, 8-dihydro-2' deoxyguanine (8-oxoG) as the histologic grade progressed. ADC, Adenocarcinoma; $S C C$, squamous cell cancer.

performed with analysis of variance for repeated measures, followed by the Fisher least-significant-difference test of repeated measures when appropriate. Comparisons between groups were performed with factorial analysis of variance, followed by the Fisher least-significant-difference test of repeated measures.

\section{Results}

A total of 120 animals underwent surgical intervention, half $(n=60)$ of which received MNAN. There were 20 deaths before the conclusion of the experiment. Most of the causes for death were related to obstruction and bronchopneumonia in the animals. A total of 15 animals from the reflux-only group had adenocarcinoma, and 19 animals from the reflux with MNAN group had squamous cell cancer. Both groups had stepwise progression of the cancers through stages of esophagitis, Barrett's esophagus, dysplasia, squamous hyperplasia, and adenocarcinoma and squamous cell cancers. There were tumors with adenosquamous histology, which is typical of the rat reflux model (Figure E1).

When the expression of 8-oxoG was examined in the varying degrees of histologic severity, it showed a gradual increase as the lesions progressed toward cancerous differentiation (Figure 1). It was upregulated several fold in adenocarcinoma and squamous cell cancers. Dysplastic lesions had significantly higher staining for 8-oxoG when compared with Barrett's and squamous premalignant lesions, such as papillomatosis.

There was significantly more DNA damage in both adenocarcinoma and squamous cell cancers when compared with that seen in control animals not undergoing operations in terms of 8-oxoG staining (Figure 1). When
OGG1 staining density was compared between animals with adenocarcinoma and squamous cell cancers, the former had increased staining compared with the latter (Figure 2).

Expression of $O G G 1$ was increased in Barrett's, Barrett's dysplasia, and adenocarcinoma, the latter with the highest staining intensity (Figure E2). The staining was both nuclear and perinuclear in nature. Squamous premalignant lesions, such as papillomas, had an increased staining compared with that seen in the normal esophageal mucosa. However, the staining intensity was lower in both squamous dysplasias and squamous cell cancers (Figure 2).

Staining scores for both caspase-dependent and caspase-independent pathway markers was higher as the lesions progressed toward cancers (Figure 3). We used immunohistochemical staining for caspase-3, PARP, AIF, and cytochrome $\mathrm{C}$ to investigate the pathways involved in apoptosis (Figures E3-E5); both mechanisms seem to be working in this malignant progression process. Apoptosis found in the cells correlated well with 8-oxoG staining.

Protein expression by means of Western blotting mirrored functionally the above immunohistochemical staining patterns, with downregulation of $O G G 1$ in squamous cell cancers when compared with adenocarcinoma (Figure 4). Caspase-3 was predominantly upregulated in adenocarcinoma and squamous cell cancers. Western blotting for AIF showed upregulation in Barrett's, Barrett's with dysplasia, carcinoma in situ, and adenocarcinoma. It was not expressed significantly in squamous dysplasia 


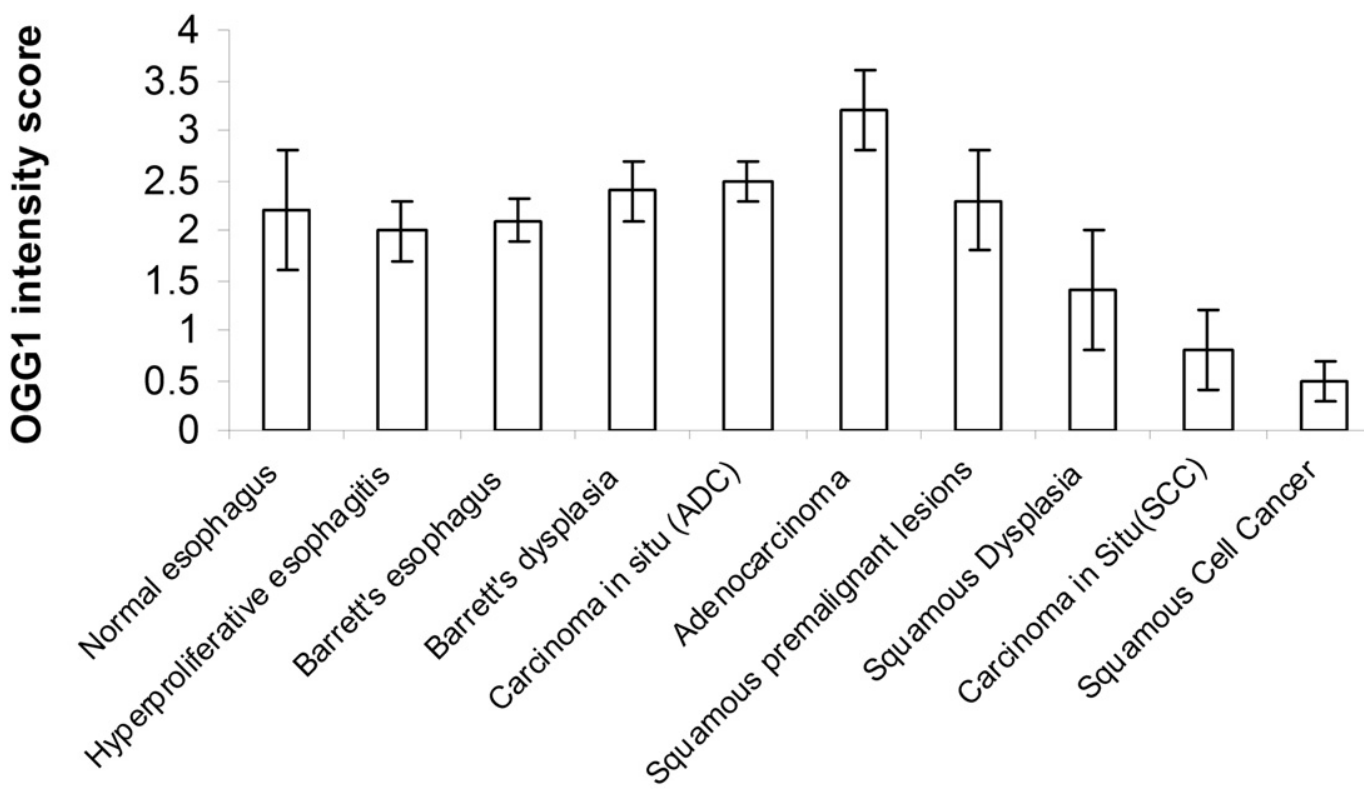

Figure 2. Staining score intensity for 8-oxoguanine DNA glycosylase (OGG1) as per varying histologic grades. ADC, Adenocarcimona; SCC, squamous cell cancer.

but showed increased expression in squamous cell cancer. The apoptotic marker PARP was significantly more expressed in squamous dysplasia and squamous cell cancers.

\section{Discussion}

The significant finding from the current investigation is that GERD leads to progressive DNA damage. However, the repair processes seem to be different among the 2

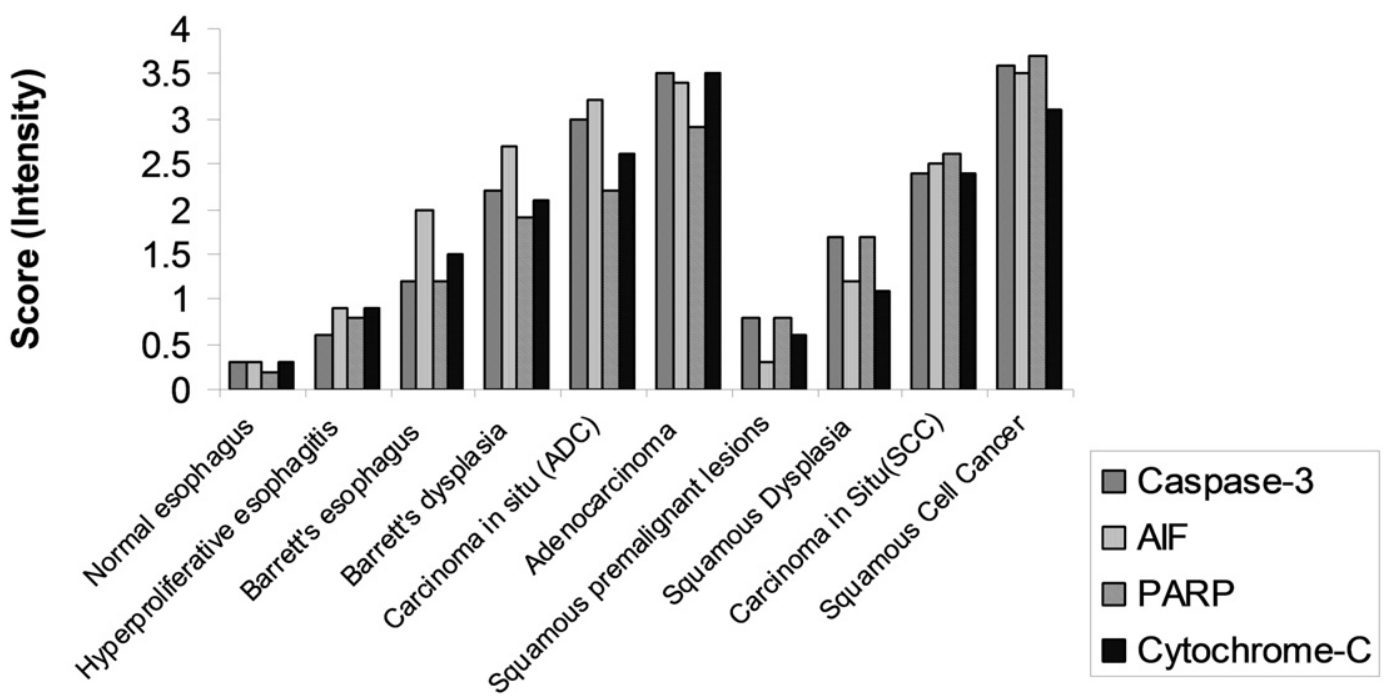

Figure 3. Caspase-dependent and caspase-independent pathway activity as per staining intensity in varying histologic grades. ADC, Adenocarcimona; SCC, squamous cell cancer; AIF, apoptosis inducible factor; PARP, poly (adenosine diphosphate-ribose) polymerases. 


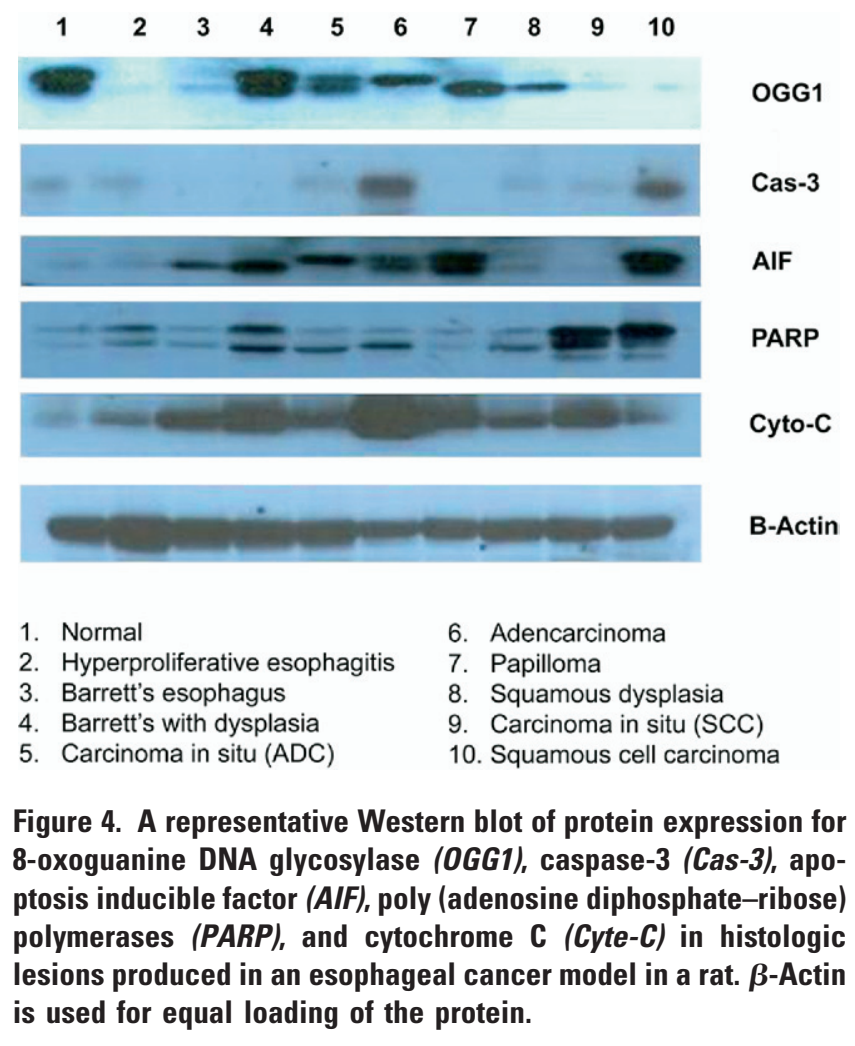

histologic subtypes of esophageal cancer. We found that the BER pathway is significantly downregulated in squamous cell cancers as opposed to adenocarcinomas.

GERD can lead to production of ROS in esophageal mucosa. ${ }^{19,20}$ Animal studies have demonstrated the mutagenic potential of refluxate in an animal model of esophageal cancer. ${ }^{21}$ Oxidative stress has been shown to play an important role in the GERD-associated esophageal cancer progression. ${ }^{10}$ Other studies suggest that antioxidants are protective toward development of reflux esophagitis and might prevent malignant progression. ${ }^{22}$

Oxidative stress injury can lead to harmful DNA adduct formation, of which 8-oxoG is the most stable and deleterious adduct. ${ }^{23}$ This has been shown to lead to mismatch in base pairs by polymerases during the DNA replication phase. If not repaired properly, it can lead to $\mathrm{G}: \mathrm{C} \rightarrow \mathrm{T}: \mathrm{A}$ transversion. Different pathways undertake DNA repair and are specific to the type of DNA damage. ${ }^{23}$ BER operates on small lesions, such as oxidized or reduced bases, fragmented adducts, or those produced by methylating agents. The single damaged base is removed by base-specific DNA glycosylases; for example, the exposure to ROS can lead to 8-oxoG, and as described above, this is excised by $O G G 1 .^{14}$ The abasic site is then restored by endonuclease action, re moval of the sugar residue, DNA synthesis with the other strand as a template, and ligation. A reduced ability to excise 8-oxoG can lead to accumulation of ROS-induced mutations. ${ }^{14}$

Association between the Ser326Cys polymorphism in $O G G 1$ in patients with esophageal cancer from Linxian, China, found that homozygosity for the Cys/Cys genotype significantly increased the risk of development of esophageal squamous cell carcinoma. ${ }^{15}$ In another study polymorphism analysis in a white population with orolaryngeal cancer when compared with control subjects showed an increased risk for orolaryngeal cancer for both the hOGG1 326(Ser)/326(Cys) and hOGG1 326(Cys)/326(Cys) genotypes. ${ }^{24} \mathrm{~A}$ similar increased risk for lung cancer, ${ }^{14}$ colorectal cancer, ${ }^{25}$ stomach cancer, ${ }^{26}$ and prostate cancer ${ }^{27}$ has been reported related to polymorphisms involving $O G G 1$. Studies from Mut-Y homologue and $O G G 1$ knockout mice suggest accumulation of 8-oxoG adducts and predisposition to cancer in the aerodigestive tract. ${ }^{28}$ Urinary concentration of 8-oxoG is reported to be 50 times higher in patients with cancers when compared with that in control subjects. ${ }^{29}$

Antitumor action of several chemotherapeutic agents, such as platinum, is based on forming DNA adducts. Drug resistance in cancer cells can develop because of the enhanced DNA repair capacity through the DNA repair pathways. Several new therapeutic targets are emerging based on the DNA repair genes to develop novel anticancer therapies. Additionally, such genes might provide predictive and prognostic value in tumor biology. ${ }^{16,17,30}$

In the present study we found increased accumulation of 8-oxoG adducts, as demonstrated by means of immunohistochemistry, when the esophagus was subjected to chronic gastroduodenal reflux. This was reflected in the increased expression in Barrett's and dysplastic Barrett's. Subsequent high expression in an adenocarcinoma specimen might suggest that there is inadequate repair of this lesion, which might be responsible for malignant progression. Similar findings were observed in the squamous premalignant lesions, squamous dysplasia, and squamous cell cancers of the esophagus when subjected to MNAN treatment. The BER pathway was predominantly active in adenocarcinoma but not in squamous cell cancer. This is reflected in the increased $O G G 1$ activity in esophageal adenocarcinoma but not esophageal squamous cell cancer in this rat model. This has important implications regarding identifying new chemotherapeutic agents and assessing response to therapy. The differential activation of the DNA repair mechanism in the histologic subtypes of esophageal cancer might signify how a mutagenic signal is handled in the malignant progression of these cancers. Apoptosis in this progressive malignant transformation model suggests that it is modulated through both caspase-dependent and caspase-independent pathways. Our previous study investigating the role of Mut-Y homologue, which is responsible for directly repairing the 8-oxoG adduct through the mismatch repair pathway, 
showed that Mut-Y homologue is increasingly exhausted in tissues subjected to chronic reflux-related esophageal injury (unpublished data). This might result because of the disparity between the ability to repair DNA damage and subsequent progression to cancer. The downregulation of the BER pathway in squamous cell cancers might have been due to mutations in $O G G 1$; however, in the present investigation we did not study mutations in these genes. Alternative repair mechanisms are known to act on 8-oxoG adducts. For example, pol- $\beta$ cells are able to repair these lesions in the absence of $O G G 1$ and are mediated through pol- $\delta / \varepsilon$-mediated BER (long-patch BER) pathway. ${ }^{14}$

There are inherent limitations in the present investigations because we used an animal model. Caution needs to be exercised while extrapolating results from this study to human disease processes. These models are based on bypassing or excluding the stomach to achieve predominantly biliary reflux. Models that bypass the stomach or are based on gastrectomy to achieve esophagojejunal reflux include animals with severe nutritional deficiency and that have been shown to develop no tumors in the presence of gastric acid, which is contrary to a clinical scenario in which both gastric and biliary reflux is a common occurrence in GERD. Another model using a side-to-side esophagoduodenal anastomosis is used in conjunction with iron administration. However, any direct evidence of the role of iron overload in reflux-induced esophageal adenocarcinoma in human subjects is lacking. Additionally, none of these models have thus far reported any evidence of distant metastasis. We have addressed these concerns by achieving mixed gastroduodenal reflux in the lower esophagus, which mimics the human situation. Tissue available for processing is limited because of the small size of the rat esophagus, limiting parallel extensive experiments to be performed. Another disadvantage of the model is the long duration needed to produce malignant changes, but this might be a reflection of the malignant process itself, where there is a long latent period between exposure to gastroduodenal contents and the development of esophageal cancer.

The present study raises important questions regarding the role played by the BER pathway in reflux-induced and carcinogen-treated cancers in an animal model. This pathway appears to be differentially upregulated in the histologic subtypes in rat esophageal cancer and might play an important role in esophageal carcinogenesis in the rat.

\section{References}

1. Blot WJ, Devesa SS, Kneller RW, Fraumeni JF Jr. Rising incidence of adenocarcinoma of the esophagus and gastric cardia. JAMA. 1991;265: 1287-9.

2. Pohl H, Welch HG. The role of overdiagnosis and reclassification in the marked increase of esophageal adenocarcinoma incidence. $J$ Natl Cancer Inst. 2005;97:142-6.
3. Lagergren J, Bergstrom R, Lindgren A, Nyren O. Symptomatic gastroesophageal reflux as a risk factor for esophageal adenocarcinoma. N Engl J Med. 1999;340:825-31.

4. Green JA, Amaro R, Barkin JS. Symptomatic gastroesophageal reflux as a risk factor for esophageal adenocarcinoma. Dig Dis Sci. 2000;45: 2367-8.

5. Attwood SE, Smyrk TC, DeMeester TR, Mirvish SS, Stein HJ, Hinder RA. Duodenoesophageal reflux and the development of esophageal adenocarcinoma in rats. Surgery. 1992;111:503-10.

6. Miwa K, Sahara H, Segawa M, et al. Reflux of duodenal or gastroduodenal contents induces esophageal carcinoma in rats. Int $J$ Cancer. 1996;67:269-74.

7. Sato T, Miwa K, Sahara H, Segawa M, Hattori T. The sequential model of Barrett's esophagus and adenocarcinoma induced by duodeno-esophageal reflux without exogenous carcinogens. Anticancer Res. 2002;22:39-44.

8. Farhadi A, Fields J, Banan A, Keshavarzian A. Reactive oxygen species: are they involved in the pathogenesis of GERD, Barrett's esophagus, and the latter's progression toward esophageal cancer? Am J Gastroenterol. 2002;97:22-6.

9. Liu L, Ergun G, Ertan A, Woods K, Sachs I, Younes M. Detection of oxidative DNA damage in oesophageal biopsies of patients with reflux symptoms and normal pH monitoring. Aliment Pharmacol Ther. 2003; 18:693-8.

10. Sihvo EI, Salminen JT, Rantanen TK, et al. Oxidative stress has a role in malignant transformation in Barrett's oesophagus. Int $J$ Cancer. 2002;102:551-5.

11. Ames BN, Gold LS. Endogenous mutagens and the causes of aging and cancer. Mutat Res. 1991;250:3-16.

12. Cheng KC, Cahill DS, Kasai H, Nishimura S, Loeb LA. 8Hydroxyguanine, an abundant form of oxidative DNA damage, causes G----T and A----C substitutions. J Biol Chem. 1992;267: 166-72.

13. Moriya M, Grollman AP. Mutations in the mutY gene of Escherichia coli enhance the frequency of targeted $\mathrm{G}: \mathrm{C} \rightarrow \mathrm{T}: \mathrm{A}$ transversions induced by a single 8-oxoguanine residue in single-stranded DNA. Mol Gen Genet. 1993;239:72-6.

14. Goode EL, Ulrich CM, Potter JD. Polymorphisms in DNA repair genes and associations with cancer risk. Cancer Epidemiol Biomarkers Prev. 2002;11:1513-30.

15. Xing DY, Tan W, Song N, Lin DX. Ser326Cys polymorphism in hOGG1 gene and risk of esophageal cancer in a Chinese population. Int J Cancer. 2001;95:140-3.

16. Belzile JP, Choudhury SA, Cournoyer D, Chow TY. Targeting DNA repair proteins: a promising avenue for cancer gene therapy. Curr Gene Ther. 2006;6:111-23.

17. Madhusudan S, Middleton MR. The emerging role of DNA repair proteins as predictive, prognostic and therapeutic targets in cancer. Cancer Treat Rev. 2005;31:603-17.

18. Lin H, Roseborough G, Dong Y, Williams GM, Wei C. DNA damage and repair system in spinal cord ischemia. J Vasc Surg. 2003;37:847-58

19. Wetscher GJ, Hinder RA, Klingler P, Gadenstatter M, Perdikis G, Hinder PR. Reflux esophagitis in humans is a free radical event. Dis Esophagus. 1997;10:29-33.

20. Olyaee M, Sontag S, Salman W, et al. Mucosal reactive oxygen species production in oesophagitis and Barrett's oesophagus. Gut. 1995;37:168-73.

21. Theisen J, Peters JH, Fein M, et al. The mutagenic potential of duodenoesophageal reflux. Ann Surg. 2005;241:63-8.

22. Lee JS, Oh TY, Ahn BO, et al. Involvement of oxidative stress in experimentally induced reflux esophagitis and Barrett's esophagus: clue for the chemoprevention of esophageal carcinoma by antioxidants. Mutat Res. 2001;480-481:189-200.

23. Fortini P, Pascucci B, Parlanti E, D’Errico M, Simonelli V, Dogliotti E. 8-Oxoguanine DNA damage: at the crossroad of alternative repair pathways. Mutat Res. 2003;531:127-39.

24. Elahi A, Zheng Z, Park J, Eyring K, McCaffrey T, Lazarus P. The human $O G G 1$ DNA repair enzyme and its association with orolaryngeal cancer risk. Carcinogenesis. 2002;23:1229-34. 
25. Kim JI, Park YJ, Kim KH, et al. hOGG1 Ser326Cys polymorphism modifies the significance of the environmental risk factor for colon cancer. World J Gastroenterol. 2003;9:956-60.

26. Takezaki T, Gao CM, Wu JZ, et al. hOGG1 Ser(326)Cys polymorphism and modification by environmental factors of stomach cancer risk in Chinese. Int J Cancer. 2002;99:624-7.

27. Trzeciak AR, Nyaga SG, Jaruga P, Lohani A, Dizdaroglu M, Evans MK. Cellular repair of oxidatively induced DNA base lesions is defective in prostate cancer cell lines, PC-3 and DU-145. Carcinogenesis. 2004;25:1359-70.

28. Russo MT, De Luca G, Degan P, et al. Accumulation of the oxidative base lesion 8-hydroxyguanine in DNA of tumor-prone mice defective in both the Myh and Ogg1 DNA glycosylases. Cancer Res. 2004;64: 4411-4.

29. Rozalski R, Gackowski D, Roszkowski K, Foksinski M, Olinski R. The level of 8-hydroxyguanine, a possible repair product of oxidative DNA damage, is higher in urine of cancer patients than in control subjects. Cancer Epidemiol Biomarkers Prev. 2002;11:1072-5.

30. Manic S, Gatti L, Carenini N, Fumagalli G, Zunino F, Perego P. Mechanisms controlling sensitivity to platinum complexes: role of p53 and DNA mismatch repair. Curr Cancer Drug Targets. 2003;3:21-9.

\section{Discussion}

Dr David R. Jones (Charlottesville, $\mathrm{Va}$ ). Dr Bonde, that was a very nice presentation.

I have just 2 questions for you. Is the $O G G 1$ downregulated in either acidic or basic conditions that are frequently associated with the development of Barrett's epithelial changes or adenocarcinoma of the esophagus?
Dr Bonde. This particular model uses both gastric and duodenal reflux - that is, both acidic and alkaline reflux - to create this model. Therefore it was downregulated in terms of squamous cell cancers in both of them. However, we did not study the specific effect of the refluxate on the $O G G 1$ expression in this current study.

Dr Jones. There are some data that reversing the continued insult of acid and bile into the esophagus will actually cause the Barrett's changes to regress. Do you have any data on the regression of the changes in the 8-oxoG levels if you were to reverse this surgically created reflux model?

Dr Bonde. That is a very interesting question, and that is the one question that we would like to answer. It is known that the 8-oxoG concentration is higher in patients with esophageal cancer and in many cancers, particularly in the urine. We have mice models now that are specifically $O G G 1$ knockout models, and to try this model in those mice will be the next plausible step to see whether there is a decrease in the incidence of Barrett's in those mice. However, there are other ways of delivering this gene through gene therapy locally into the esophagus and seeing whether treatment with $O G G 1$ really regresses the Barrett's metaplasia in this model.

Dr Jones. Thank you. That was a very nice presentation.

Dr Bonde. Thank you. 




Hyperproliferative esophagitis

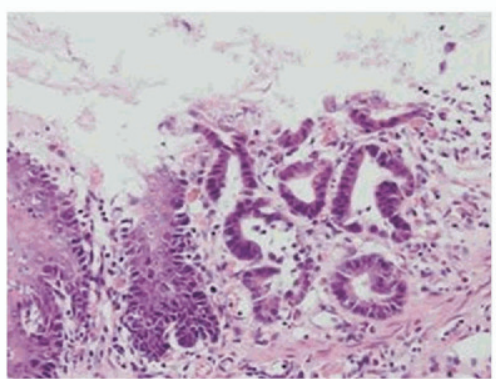

A Barrett's dysplasia

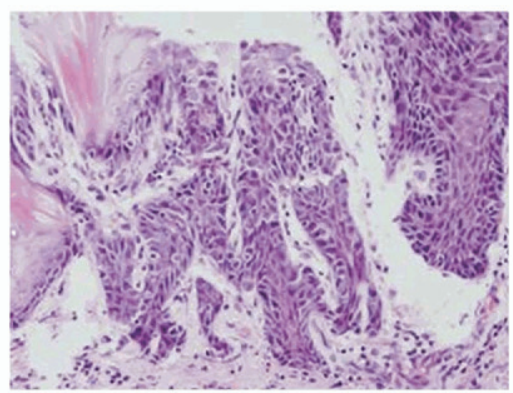

Squamous Dysplasia



Barrett's esophagus

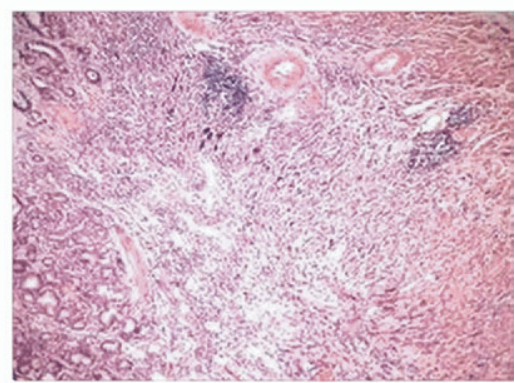

Adenocarcinoma

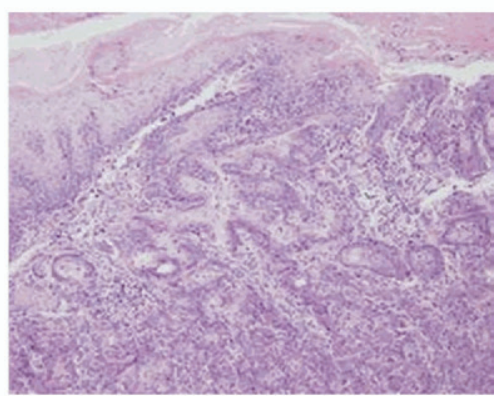

Squamous cell cancer

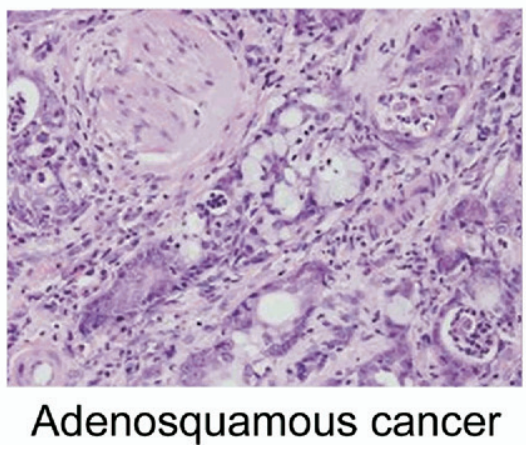

Figure E1. A, Reflux-induced esophageal tumor histology. A representative high-magnification photomicrograph of the esophageal mucosa subjected to surgically induced reflux showing hyperproliferative esophagitis in the rat esophagus, columnar metaplasia, high-grade dysplasia showing nuclear atypia, and a representative adenocarcinoma in the rat esophagus. B, A representative section showing squamous dysplasia, squamous cell cancer invading the esophageal wall, and a typical adenosquamous lesion, which is common in surgically induced rat reflux model with features of both squamous cell cancer and adenocarcinoma. 


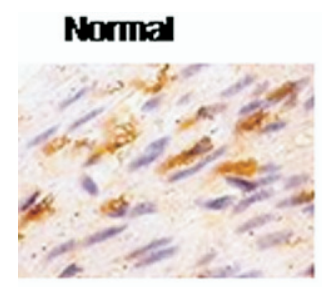

\section{Esophagitis}
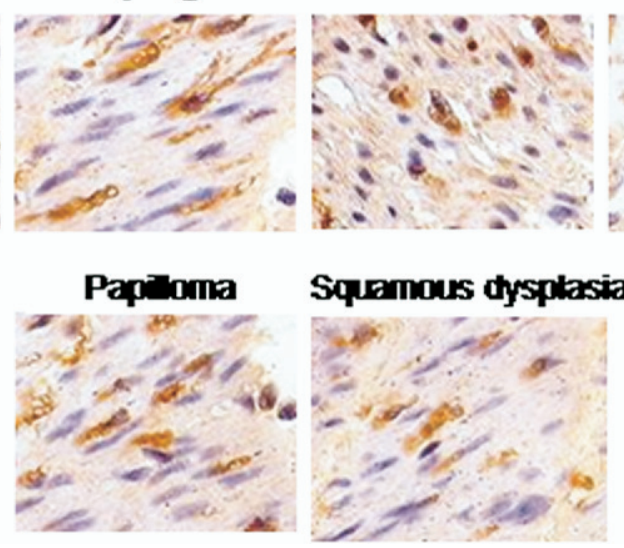

Barett's
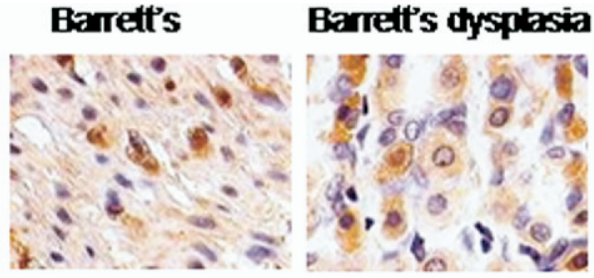

\section{Adenocatinoma}

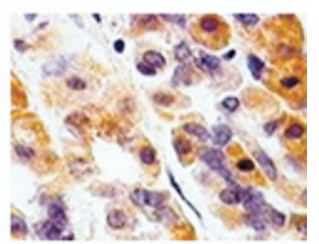

Figure E2. Differential staining of 8-oxoguanine DNA glycosylase (OGG1) in histologic progression from normal to adenocarcinoma and progression to squamous cell cancer (SCC).


Figure E3. Immunohistochemical staining for caspase-3 in the histologically progressive lesions in reflux-induced esophageal cancer in the rat. SCC, Squamous cell cancer. 

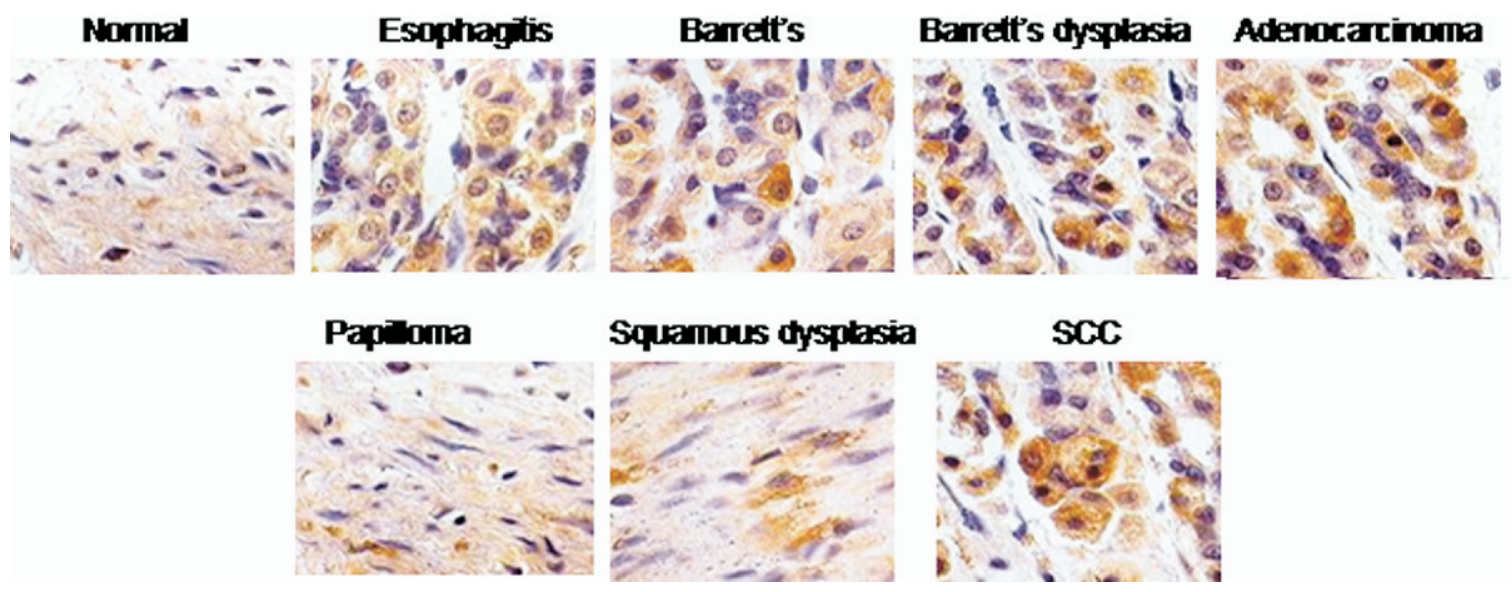

Figure E4. Immunohistochemical staining for apoptosis inducible factor (AIF) in the serial histologic progression from normal to adenocarcinoma and normal to squamous cell cancer (SCC) in the rat reflux-induced tumor model.

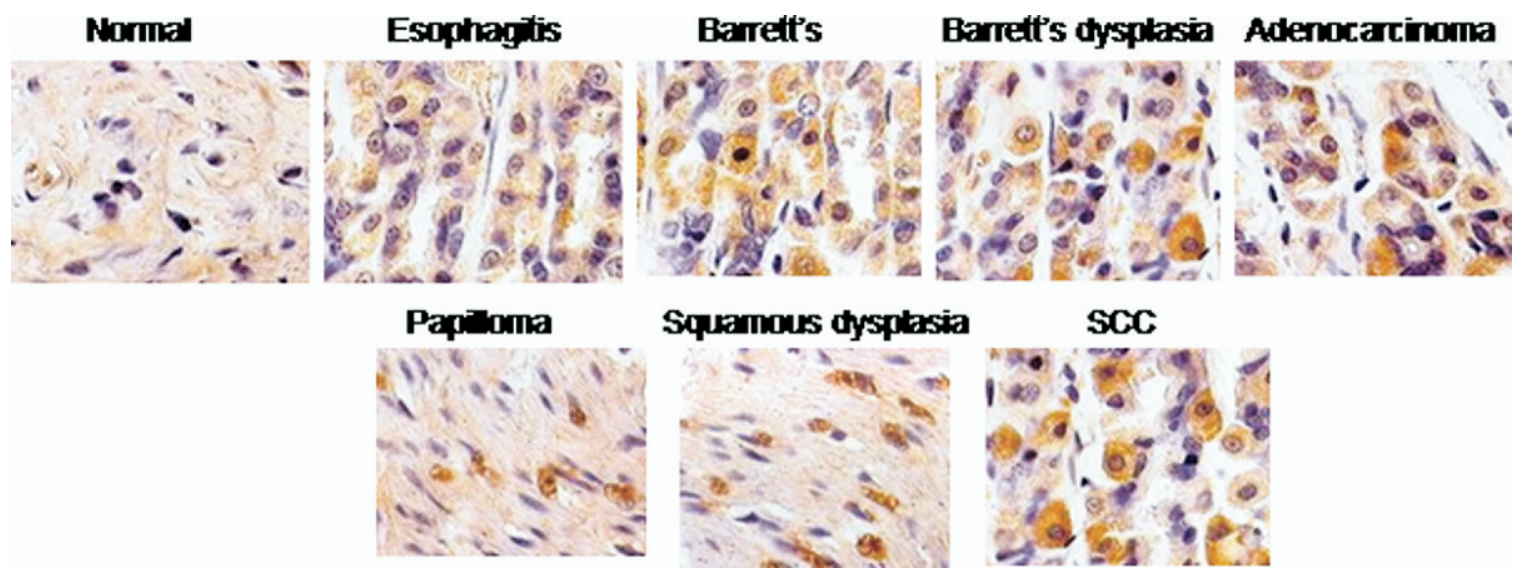

Figure E5. Immunohistochemical staining for poly (adenosine diphosphate-ribose) polymerases (PARP) in the progressive lesions produced by reflux in the rat esophageal cancer model. SCC, Squamous cell cancer. 